\title{
PAROTID TUBERCULOSIS- A CASE REPORT
}

\author{
Puneet Kumar Agarwal1, Mayank Badkur², Chirag Shanti Dausage ${ }^{3}$
}

${ }^{1}$ Assistant Professor, Department of Surgery, AIIMS, Bhopal.

${ }^{2}$ Senior Resident, Department of Surgery, AIIMS, Bhopal.

${ }^{3}$ Senior Resident, Department of Surgery, AIIMS, Bhopal.

HOW TO CITE THIS ARTICLE: Agarwal PK, Badkur M, Dausage CS. Parotid tuberculosis- a case report. J. Evolution Med. Dent. Sci. 2017;6(83):5820-5821, DOI: 10.14260/jemds/2017/1263

\section{PRESENTATION OF CASE}

A 24-year-old male presented with history of swelling over right parotid area and angle of mandible, which on examination revealed a lump in the right parotid area. Ultrasonography of the lump showed a hypoechoic area in the superficial lobe of right parotid gland. Image guided fine needle aspiration from the right parotid lump yielded purulent material, and the smears on Ziehl-Neelsen (ZN) staining for acid-fast bacilli (AFB) was positive. Patient was conservatively treated on anti-tubercular treatment on lines of parotid tuberculosis. Patient responded well and on subsequent followup swelling subsided.

Tuberculosis in Parotid gland is a rare form of extrapulmonary tuberculosis. In an endemic country like India also, parotid gland tuberculosis is very uncommon.[1][2] Till date only a few cases have been reported; that too from parotidectomy specimens,[3] it presents as a swelling in the parotid region. However, tuberculosis of parotid necessitates adequate and appropriate treatment ${ }^{[4]}$ and if treated properly the prognosis of tuberculosis of the parotid gland is very good. We report a case of parotid tuberculosis, who responded well to anti-tubercular treatment.

\section{DIFFERENTIAL DIAGNOSIS}

It usually presents as a slow-growing mass indistinguishable from a malignancy. On imaging also, tuberculosis of the parotid may mimic neoplasm. The differential diagnosis includes benign malignant neoplastic diseases of the parotid and sarcoidosis.

\section{CLINICAL DIAGNOSIS}

Preoperative diagnosis is difficult and the symptomatology is nonspecific. Clinical symptoms vary from an acute infectious process to an indolent chronic presentation. Parotid gland TB mostly presents as a localised and progressive chronic swelling. It usually presents as a unilateral swelling or abscess involving the parenchyma of the gland, either through haematogenous spread or from infection of lymph nodes within or around it. It may also involve both the parotids.

'Financial or Other Competing Interest': None.

Submission 29-05-2017, Peer Review 02-10-2017,

Acceptance 09-10-2017, Published 16-10-2017.

Corresponding Author:

Dr. Mayank Badkur,

Senior Resident,

Department of Surgery,

AIIMS, Bhopal.

E-mail: drmayankbadkur@gmail.com

DOI: $10.14260 /$ jemds $/ 2017 / 1263$

\section{PATHOLOGICAL DISCUSSION}

In cases when the parotid gland is involved, there usually is a primary pulmonary focus, and blood and lymphatic spread are the most probable causes of secondary infection routes. If a primary disease focus is not found the infection is clinically called primary tuberculosis of the gland, which can impair diagnosis, since it is very similar to parotid tumours. The disease is rare, because of an inhibiting effect saliva has over the mycobacterium.

\section{DISCUSSION OF MANAGEMENT}

Parotid tuberculosis is an unusual form of extrapulmonary tuberculosis. It usually presents as a unilateral swelling or abscess involving the parenchyma of the gland either through haematogenous spread or from infection of lymph nodes within or around it. It can occur bilaterally involving both the parotids.[5] First case of parotid gland tuberculosis was described by C De Paoli in 1893.[6] Since then only one hundred cases have been described in the literature, mostly on histopathological examination of the parotidectomy specimen.[7]

Direct expansion of the bacilli from the oral cavity to parotid gland, by means of the gland ductal system is the well-known course for the transmission of contamination. ${ }^{[8]}$ Sometimes intraparotid and periparotid lymph nodes may get tainted either by lymphatic drainage from the oral cavity or haematogenously from a pulmonary focus. Parotid tuberculosis can present as acute infectious or as an indolent chronic infection.

Ultrasound is the modality of choice for the evaluation of palpable abnormalities of the parotid gland and also of suspected parotid calculus disease.[9] Sonographically, parotid tuberculosis can be of two sorts, in particular parenchymal and periparotid type. The parenchymal type shows up as a diffusely enlarged, relatively hypoechoic gland, with or without focal intraparotid anechoic zones which may have a cavity or depressions inside. The periparotid type appears as hypoechoic nodules situated in the fringe zone of the hyperechoic parotid gland consistent with enlarged periglandular lymph nodes.[10] USG-guided fine needle aspiration cytology has a general exactness of $86 \%-89 \%$ to decide the histological diagnosis.[11,12] Rifampicin, isoniazid, ethambutol and pyrazinamide the four drug regimen is given in the intensive phase followed by two drugs (rifampicin and isoniazid) in continuation phase is a recommended treatment.[13] The incite analysis and doubt is the key to block the requirement for surgery and parotidectomy can be evaded in a medicinally treatable condition.[14]

\section{FINAL DIAGNOSIS}

Parotid gland tuberculosis, although rare must be considered as part of the differential diagnosis of tumour masses in the parotid gland, especially in immunocompromised patients. 
Definitive diagnosis can be difficult, but it is important because of the similarities between this disease and neoplasm, and treatment plan can be greatly affected depending upon the pathology.

\section{REFERENCES}

[1] Janmeja AK, Das SK, Kochhar S, et al. Tuberculosis of the parotid gland. Indian J Chest Dis Allied Sci 2003;45(1):67-9.

[2] Kant R, Sahi RP, Mahendra NN, et al. Primary tuberculosis of the parotid gland. J Indian Med Assoc 1977;68(10):212.

[3] Bhargava S, Watmough DJ, Chisti FA, et al. Case report: tuberculosis of the parotid gland: diagnosis by CT. Br J Radiol 1996;69(828):1181-3.

[4] William N, Rom, Stuart M, et al. Tuberculosis of the salivary glands: tuberculosis. $1^{\text {st }}$ edn. Little, Brown \& Company 1996: p. 572.

[5] Suleiman AM. Tuberculous parotitis: report of 3 cases. Br J Oral Maxillofac Surg 2001;39(4):320-3.

[6] Chaudhary S. Colour Atlas and Text of the salivary glands. In: Norman JE, McGurk M. eds. London: MosbyWolfe 1997:337-9.
[7] Sikora AG, Rothstein SG, Garay KF, et al. Tuberculosis of the head and neck. In: Rom WN, Garay SM. eds. Tuberculosis. $2^{\text {nd }}$ edn. Philadelphia: Lippincott Williams and Wilkins 2004:477-88.

[8] Howlett DC. High resolution ultrasound assessment of the parotid gland. Br J Radiol 2003;76(904):271-7.

[9] Kushwaha RA, Kant S, Verma SK, et al. Isolated metacarpal bone tuberculosis: a case report. Lung India 2008;25(1):17-9.

[10] Chou YH, Tiu CM, Liu CY, et al. Tuberculosis of the parotid gland: sonographic manifestations and sonographically guided aspiration. J Ultrasound Med 2004;23(10):1275-81.

[11] He Y, Zhang ZY, Tian Z. The diagnostic value of fineneedle aspiration cytology (FNAC) for lesions in the parotid gland. Shanghai Kou Qiang Yi Xue 2003;12(6):410-3.

[12] World Health Organization. Treatment of tuberculosis. Guidelines for national programs. Geneva: WHO, 2003. WHO/CDS/TB/2003.313.

[13] Franzen A, Franzen CK, Koegel K. Tuberculosis of the parotid gland: a rare differential diagnosis of parotid tumor. Laryngo-Rhino-Otologie 1997;76(5):308-11. 